\title{
Lipid and fatty acid profile of liver in relation to reproduction in the small-scaled terapon Terapon puta (Cuvier, 1829) from Pondicherry Coast, India
}

\author{
R. NANDIKESWARI AND M. SAMBASIVAM \\ Department of Zoology, JNRM (Govt. P. G. College) (Pondicherry University), Port Bair - 744 104, Andaman and \\ Nicobar Islands, India \\ e-mail: navinpraem@gmail.com
}

\section{ABSTRACT}

\begin{abstract}
The total lipid content as percentage of dry weight of liver of Terapon puta (Cuvier, 1829) varied at four different stages viz., immature, maturing, mature and spent stages of reproduction. Highest levels of saturated fatty acids (SFA) was recorded in the liver of mature fishes $(50.71 \%)$ followed by maturing $(48.03 \%)$ and the lowest in immature fishes $(38.91 \%)$. Highest levels of monounsaturated fatty acids (MUFA) were observed in the liver of maturing fishes $(37.07 \%)$ followed by mature $(34.09 \%)$ and the lowest levels in immature fishes (30.48\%). Maturing fishes had higher liver polyunsaturated fatty acid levels (PUFA) (13.54\%), compared to immature (10.55\%) and mature fishes $(10.17 \%)$.
\end{abstract}

Keywords: Fatty acid profile, Lipid dynamics, Pondicherry coast, Reproduction, Terapon puta

\section{Introduction}

Fish is a substantial source of food for humans and is a key component in many natural food webs. It is one of the sources of biologically valuable protein, fats and fat-soluble vitamins and plays a vital role in human nutrition, as it also forms an important source of trace minerals and calcium. Fish also provides calories, nutrients such as fat, vitamins (B complex and D), elements such as, phosphorus, sodium as well as trace elements $(\mathrm{Mn}, \mathrm{Mg}$, Zn.) (Sofia, 2005)

An increasing amount of evidences suggest that due to high content of polyunsaturated fatty acids (PUFA). fish flesh and fish oil are beneficial in reducing the serum cholesterol (Stansby, 1985). The omega-3 polyunsaturated fatty acid is recognised as an important remedy to prevent coronary heart diseases (Edirisinghe et al., 1998). It is recommended by cardiologists to use generous quantities of fish in food to obtain adequate protein without taking in excess fats and lipids (Dyerberg, 1986; Kinsella, 1991).

Fatty acid (FA) composition of fishes has unique features compared to fatty acids from other sources. Fish lipids are generally characterised by possessing large amounts of saturated and unsaturated fatty acids, mostly associated with triacylglycerols and minor amounts of phospholipids (Shahidi, 1998). Lipids and their constituent fatty acids, along with proteins, form the major organic constituents of fish and they play major roles as sources of metabolic energy for growth including reproduction and movement including migration. Furthermore, the fatty acids of fish lipids are rich in omega-3 long chain, highly unsaturated fatty acids (HUFA) that have particularly important roles in animal nutrition, including fish and human nutrition, reflecting their roles in critical physiological processes. Indeed, fish are the most important food source of these vital nutrients for man. Thus, the long standing interest in fish lipids seems from their abundance and their uniqueness (Tocher, 2003).

In general, biochemical composition of the whole body indicates the fish quality. Therefore, proximate biochemical composition of a species helps to assess its nutritional and edible value in terms of energy units compared to other species. Variation in biochemical composition of fish flesh may also occur within same species, depending upon the fishing ground, fishing season, age and sex of the individual and reproductive status. The spawning cycle and food supply are the main factors responsible for this variation (Love, 1980).

\section{Materials and methods}

Random samples of Terapon puta were collected from Pondicherry coastal waters (Bay of Bengal), at monthly intervals during 2010. Fishes were held in ice until analysis. Dissection and tissue sub-sampling were performed within $24 \mathrm{~h}$ of collection. The stages of development of ovaries and testes were confirmed mainly on the basis of histological preparations of gonads. For each species, sex, total length and stage of maturity were recorded. Liver samples were collected, dried and the 
lipid content was estimated. The percentage of lipid is expressed in terms of dry weight of liver tissue.

\section{Determination of total lipid content}

Total lipid content of liver tissue samples was estimated by the method of Folch et al. (1957). Lipid extraction was performed with chloroform:methanol mixture in the ratio of $2: 1$.

\section{Determination of total fatty acids}

Extraction of fatty acid (FA) was done following the method of Morrison and Smith (1964), comprising four important steps viz., saponification, methylation, extraction and base wash. Fatty acids estimation was conducted in Gas chromatograph (Thermo TRACE ULTRA GC) equipped with Mass spectrometry (TSQ QUANTUM) detector; column TR $5 \mathrm{MS}(30 \mathrm{~mm} \times 0.25 \mathrm{~mm}$ ID $\times 1 \mu \mathrm{m}$, composed of $5 \%$ phenyl $95 \%$ methyl poly siloxane), electron impact mode at $70 \mathrm{eV}$, helium $(99.999 \%)$ as carrier gas at a constant flow of $1 \mathrm{ml} \mathrm{min}^{-1}$, injector temperature $250^{\circ} \mathrm{C}$, auxiliary temperature $260^{\circ} \mathrm{C}$ and ion-source temperature $260^{\circ} \mathrm{C}$. Total GC running time was $32.02 \mathrm{~min}$. The compounds (FAME) were identified by GC-MS library (NIST and WILEY) and conformed to standard retention times.

\section{Results}

Changes in lipid content during various stages of maturity

Gonads of fishes of different maturity stages were visually examined, grouped together macroscopically. Four categories of gonads such as immature, maturing, mature and spent were considered. For each maturity stage, lipid content of liver of female fishes were quantified.

\section{Lipid content of liver}

The lipid content of liver at different stages of sexual maturity did not show significant variation in T. puta. T. puta showed two peaks of high gonadal activity in a year, one during February-March and another in August-September (Table 1).

\section{Fatty acid profile of liver at different stages of maturity}

The fatty acid levels in liver at immature, maturing and mature stages of $T$. puta are presented in Table 2; Fig. 1. The saturated fatty acids found in liver at different stages of maturity were: C12:0 Lauric acid, C14:0
Table 2. Fatty acid profile of liver of Terapon puta during different maturity stages

\begin{tabular}{|c|c|c|c|}
\hline Fatty acid & Immature & Maturing & Mature \\
\hline \multicolumn{4}{|c|}{ Saturated fatty acids (SFA) $\%$} \\
\hline$\overline{\mathrm{C} 12: 0}$ & - & 0.11 & 0.14 \\
\hline $\mathrm{C} 14: 0$ & 3.6 & 4.46 & 4.58 \\
\hline $\mathrm{C} 15: 0$ & 0.62 & 1.02 & 0.7 \\
\hline $\mathrm{C} 16: 0$ & 22.18 & 30.57 & 33.7 \\
\hline $\mathrm{C} 17: 0$ & 1.81 & 2.15 & 1.29 \\
\hline C18:0 & 10.4 & 9.49 & 10.04 \\
\hline $\mathrm{C} 20: 0$ & 0.3 & 0.18 & 0.16 \\
\hline $\mathrm{C} 22: 0$ & - & 0.05 & 0.06 \\
\hline $\mathrm{C} 24: 0$ & - & - & 0.04 \\
\hline Total & 38.91 & 48.03 & 50.71 \\
\hline \multicolumn{4}{|c|}{ Monounsaturated fatty acids (MUF) \% } \\
\hline$\overline{\mathrm{C} 14: 1}$ & - & - & 0.06 \\
\hline $\mathrm{C} 16: 1$ & 3.83 & 10.12 & 10.03 \\
\hline $\mathrm{C} 18: 1$ & 24.36 & 25.22 & 22.82 \\
\hline $\mathrm{C} 20: 1$ & 1.78 & 1.45 & 1.01 \\
\hline $\mathrm{C} 22: 1$ & 0.51 & 0.21 & 0.17 \\
\hline $\mathrm{C} 24: 1$ & - & 0.07 & - \\
\hline Total & 30.48 & 37.07 & 34.09 \\
\hline \multicolumn{4}{|c|}{ Polyunsaturated fatty acids (PUFA) \% } \\
\hline $\mathrm{C} 18: 2$ & 0.43 & 1.74 & 1.25 \\
\hline $\mathrm{C} 18: 3$ & - & 0.25 & - \\
\hline $\mathrm{C} 20: 4$ & 2.75 & 3.02 & 1.86 \\
\hline $\mathrm{C} 20: 5$ & 7.37 & 4.06 & 2.77 \\
\hline $\mathrm{C} 22: 6$ & - & 4.47 & 4.29 \\
\hline Total & 10.55 & 13.54 & 10.17 \\
\hline Total FA $\%$ & 79.9 & 98.6 & 95.0 \\
\hline
\end{tabular}

Myristic acid, C15:0 Pentadecanoic acid, C16:0 Palmitic acid, C17:0 Heptadecanoic acid, C18:0 Stearic acid, C20:0 Arachidic acid, C22:0 Behenic acid and C24:0 Lignoceric acid. Monounsaturated fatty acids (MUFA) recorded were: C14:1 Myrisloleic acid, C16:1 Palmitoleic acid, C17:1 Cis 10 Heptadecenoid acid, C18:1 Oleic acid, C19:1 Nonadecanoic acid, C20:1 Cis-11-Eicosenoic acid, C22:1 Erucateic acid and C24:1 Nervonic acid.

Among saturated fatty acids, C16:0 was present in significant quantity in liver of mature fishes (33.7\%) but its level declined in maturing fishes (30.57\%) and further reduced in immature fishes $(22.18 \%)$. C18:0 was found higher in immature stage (10.4\%) and mature stage $(10.4 \%)$ and its level reduced in maturing stage $(9.49 \%)$.

Table 1. Lipid content of liver of Terapon puta at different stages of maturity

\begin{tabular}{lll}
\hline Maturity stage of fish & Months & Mean lipid content of liver (\%) \\
\hline Immature (Stage I) & April, May and December & 3.40 \\
Maturing (Stage II) & January and June & 3.72 \\
Mature (Stage III) & February-March and August-September & 3.18 \\
Spent (Stage IV) & April and November & 2.07 \\
\hline
\end{tabular}




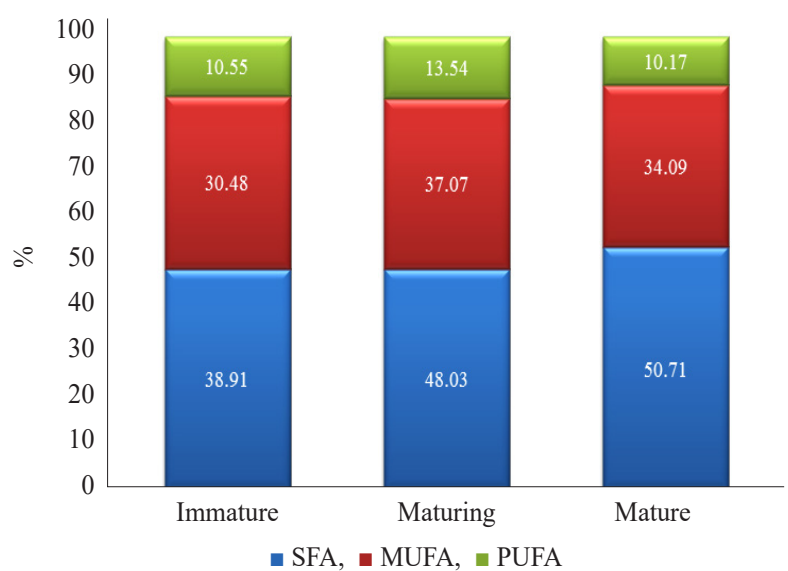

Fig. 1. Fluctuations in fatty acid levels in the liver at different stages of maturity of Terapon puta

But $\mathrm{C} 17: 0$ was less in immature stage $(1.81 \%)$ followed by mature stage $(1.29 \%)$ and increased in maturing stage $(2.15 \%)$. The percentage level of C14:0 in liver of immature fish was moderate $(3.6 \%)$ and there was a slight increase in maturing stage $(4.46 \%)$ and further increased in mature fishes $(4.58 \%)$. C15:0 was present in trace amount in immature stage $(0.62 \%)$ and in mature $(0.7 \%)$ fishes, but slightly increased in maturing fish (1.02\%). C20:0 was present in negligible amount in all the three stages of maturity. C22:0 was absent in immature stage and poorly present in liver of maturing and mature fishes. C24:0 was absent in liver of immature and maturing fishes, while poorly present in mature fish. Among the total percentage of fatty acids, saturated fatty acids were present in higher quantity in mature fishes $(50.71 \%)$ followed by maturing fish (48.03\%) and declined in immature fishes (38.91\%).

In MUFA, C18:1 was present in significant quantity in liver of maturing $(25.22 \%)$ as well as immature fish $(24.36 \%)$ and there was a slight decrease in mature fishes $(22.82 \%)$. C16:1 was fairly present in immature stage $(3.83 \%)$ and increased to considerable amount in both maturing $(10.12 \%)$ and mature $(10.03 \%)$ stages. C20:1 was present in low quantity in all the three stages, immature (1.78\%), maturing (1.45\%) and mature $(1.01 \%)$. C22:1 was present in traces in all the three stages. C24:1 was absent in immature and mature stages and was present in trace amounts in maturing fishes $(0.07 \%)$. Among the total percentage of MUFA, maturing stage had higher percentage $(37.07 \%)$ followed by mature $(34.09 \%)$ and immature fishes (30.48\%).

In PUFA, C20:5 was present in higher quantity in immature fishes $(7.37 \%)$ and it decreased in maturing stage $(4.06 \%)$ and further decreased in mature fish $(2.77 \%)$. C20:4 was present in moderate amounts in maturing fish (3.02\%), slightly decreased in immature fish $(2.75 \%)$ and decreased further in mature stage $(1.86 \%)$.
C18:2 was poorly present in immature stage $(0.43 \%)$ and increased in both mature (1.25\%) and maturing (1.74\%) fishes. C18:3 was absent in immature and mature fishes, present as traces in maturing fishes $(0.25 \%)$. C22:6 was absent in immature, but present in maturing (4.47\%) and mature fishes $(4.29 \%)$ in considerable quantities. Among the total percentage of PUFA, maturing stage had higher percentage $(13.54 \%)$ than immature $(10.55 \%)$ and mature fishes $(10.17 \%)$.

\section{Discussion}

Lipids and their constituent fatty acids have particularly important roles in the reproductive parameters of fish such as egg quality, spawning, hatching rate and survival of larvae. Lipids are utilised as energy sources throughout embryogenesis and particularly in the later stages of development prior to hatching. Eicosapentaenoic acid (EPA) and docosahexaenoic acid (DHA) are the major fatty acids in the total lipid of eggs of most fish and these fatty acids markedly influence the reproductive parameters. Fatty acids and particularly polyunsaturated fatty acids (PUFA) are functionally essential for normal growth, development and reproduction in fish (Sargent et al., 2002). In addition, arachiodonic (20: 4) acid as a major fatty acid, stimulate ovarian and testicular steroidogenesis and it is assumed to be involved in embryonic development of the immune system, hatching and early larval performance (Sorbera et al., 1998). Marine fish were found to have more unsaturated fatty acids than freshwater fish (Osman et al., 2001). Fatty acids are responsible for the fine structure of cell membrane, which makes it important for distribution of nutritional substances in the whole fish body. They also participate in the processing of cholesterol (Conner, 2000).

Not much is known about the lipid composition and fatty acid distribution in the lipid fractions of fish testis. Although the lipids of fish ovary have been examined in detail in connection to reproduction (Kaitaranta and Ackman, 1981; Tocher and Sargent, 1984; Tocher et al., $1985 \mathrm{a}, \mathrm{b})$ the polyunsaturated fatty acids in particular are known to be important for embryo growth and growth of the egg after fertilisation.

The average values of lipid content indicate that T. puta is a lean fish. The lipid content of liver was found higher in stage-II; which may be due to intensive feeding. During the preparatory phase, the lipid content was high and it declined slightly in stage-III, due to lesser intake of food at the time of spawning. The lipid level of liver was found to decline at stage-IV, which clearly indicates that lipid is mobilised from the storage sites to the development of oocytes. The clean fall in lipid content during stage-IV further indicates that energy demand for spawning activity 
is met by lipid content of the liver. Variation in the lipid content during different stages of reproductive cycle shows that they follow different reproductive strategies and lipid is one of the components that is mainly mobilised during reproduction.

The percentage frequency of fatty acids of liver at different stages of maturity in T. puta is shown in Fig. 1. The fatty acid profile of an organism changes with the change in status of the fish such as length, sex, age, season, food and environmental factors. The saturated fatty acids predominate, followed by monounsaturated fatty acids and polyunsaturated fatty acids. The fluctuations in fatty acid profile in the present study illustrate how fatty acids differ between the species and in different maturity stages. SFA and MUFA are abundant in the natural food organisms that are consumed by these fishes. In addition to that, some fatty acids are synthesised by fishes during maturation. After absorption into the body tissues, a fatty acid can be oxidised as a source of energy and converted to a different acid by elongation and unsaturation.

Among PUFA, the noticeable levels of 20:4 arachidonic acid (AA) and 20:5 (eicosapentaenoic acid) found in this species during the present study are in agreement with the results of Osman et al. (2001). Arachidonic acid (C20:4) is a precursor for prostaglandins (PG) which play an important role in fish reproduction (Stacey and Goetz, 1982) and involved in spawning activity of fishes including sperm production (Bell et al., 1986; Wade et al., 1994; Sargent et al., 1999). C20:4 possess vital function as main precursor of various eicoanoids, which have important roles in a variety of physiological functions, including osmoregulation and in the function of the reproductive system (Cejas et al., 2004).

The lipid content of tropical fish species is generally influenced by high ambient temperature and the membrane lipids of these fishes were easily fluidised even if the major fatty acids in their lipids were composed of saturated and monoenoic fatty acids (Saito et al., 1999). Lipid transfer from muscle and liver to gonad, give rise to large fluctuation of lipid content in these tissues during gonadal development (Cejas et al., 2004). The PUFA ratios of the total fatty acids in tropical and subtropical fish lipids are usually comparatively low and this is a general tendency in the lipids of marine organisms living in warm seas. However, this trend in lipid utilisation has been confirmed for only a few fish species (Saito et al., 1999). The present results revealed that the proportion of SFA were higher in this fish, while the levels of MUFA and PUFA were low. These findings are in agreement with AL-Masoodi (2012).

\section{Acknowledgements}

Authors are grateful to Pondicherry University for providing necessary facilities for carrying out this research work. Authors are grateful to the reviewers for their valuable reviews and suggestions.

\section{References}

AL-Masoodi, S. H. S. 2012. Comparative histological, ultrastructure and histochemical study of the testes from two fish species. M. Sc. Thesis, Umm AL-Qura University, Kingdom of Saudi Arabia.

Bell, M. V., Henderson, R. J. and Sargent, J. R. 1986. The role of polyunsaturated fatty acids in fish. Com. Biochem. Physiol., 83(B): 711-719.

Cejas, J. R., Almansa, E., Jerez, S., Bolanos, A., Samper, M. and Lorenzo, A. 2004. Lipid and fatty acid composition of muscle and liver from wild and captive mature female broodstocks of white seabream, Diplodus sargus. Com. Biochem. Physiol., 138: 91-102.

Conner, W. E. 2000. Importance of n-3 fatty acids in health and disease. Am. J. Clin. Nutr., 71(1): 171-176.

Dyerberg, J. 1986. Linolinate derived poly-unsaturated fatty acids and prevention of atherosclerosis. Nutr. Rev., 44: 25-31.

Edirisinghe, E. M. R. K. B., Perera, W. M. K., Tayasooriya, S. P. and Bamunuarachchi, A. 1998. Health related fatty acids in some pelagic fishes in Sri Lanka. Sri Lanka J. Aquat. Sci., 3: 97-107.

Folch, J., Lees, M. and Stanley, G. H. S. 1957. A simple method for the isolation and purification of total lipid from animal tissues. J. Biol. Chem., 226(1): 497-509.

Kaitaranta J. K. and Ackman, R. G. 1981. Total lipids and lipid classes of fish roe. Comp. Biochem. Physiol., 69: 725-729.

Kinsella, J. E. 1991. The potential role of fish and seafood in attaining nutrient balance and improving health. Mar. Technol. Soc. J., 25: 4-15.

Love, R. M. 1980. The chemical biology of fishes, vol. II, $3^{\text {rd }}$ edn. Academic Press, Inc. London, 547 pp.

Morrison, W. R. and Smith, L. M. 1964. Preparation of fatty acid methyl esters and dimethyl acetals from lipids with boron fluoride methanol. J. Lipid Res., 5: 600-608.

Osman, H., Suriah, A. R. and Law, B. C. 2001. Fatty acid composition and cholesterol content of selected marine fish in Malaysian waters. Food Chem., 73(1): 55-60.

Saito, H., Yamashiro, R., Alasalvar, C. and Konno, T. 1999. Influence of diet on fatty acids of three subtropical fish, subfamily Caesioninae (Caesio diagramma and C. tile) and family Siganidae (Siganus canaliculatus). Lipids, 34(10): 1073-1082.

Sargent, J. R., Tocher, D. R. and Bell, J. G. 2002. The lopids. In: Halver, J. E. and Hardy, R. W. (Eds.), Fish nutrition, $3^{\text {rd }}$ edn. Academic Press, San Diego, USA, p. 181-257. 
Sargent, J., Bell, G., McEvoy, L., Tocher, D. and Estevez, A. 1999. Recent developments in the essential fatty acid nutrition of fish. Aquaculture, 177: 191-199.

Shahidi, F. 1998. Seat fishery and product development, Science Tech Publishing Company, St. John's, Canada, p.109-111.

Sofia 2005. Metal contamination in commereclally important fish and shrimp species collected from Acea (Indonesia), Penang and Perak (Malaysia), M. Sc. Thesis, Universiti Sain Malaysia, Malaysia, $163 \mathrm{pp}$.

Sorbera, L. A., Zanuy, S. and Carrielo, M. 1998. A role for polyunsaturated fatty acids and prostaglandins in oocyte maturation in the seabass (Dicentrarchus labrax). Trends Comp. Endocrinol. Neurobiol., 839: 535-537.

Stacey, N. E. and Goetz, F. W. 1982. Role of prostaglandins in fish reproduction. Can. J. Fish. Aquat. Sci., 39: 92-98.

Stansby, M. 1985. Fish or fish oil in the diet and heart attack. Mar. Fish. Rev., 46(2): 60-63.
Tocher, D. R. 2003. Metabolism and functions of lipids and fatty acids in teleost fish. Rev. Fish. Sci., 11(2): 107-184.

Tocher, D. R., Fraser, A. J., Sargent, J. R. and Gamble, J. C. 1985a. Fatty acid composition of phospholipids and neutral lipids during embryonic and early larval development of Atlantic herring (Clupae harengus L.). Lipids, 20(2): 69-74.

Tocher, D. R., Fraser, A. J., Sargent, J. R. and Gamble, J. C. 1985b. Lipid class composition during embryonic and early larval development in Atlantic herring (Chupea harengus L). Lipids, 20(2): 84-89.

Tocher, D. R. and Sargent, J. R. 1984. Analysis of lipids and fattyacids in ripe roes of some north-west European marine fish. Lipids, 19: 492-499.

Wade, M. G., Kraak, V. D. G., Gerrits, M. F. and Ballantyne, J. S. 1994. Release and steroidogenic actions of polyunsaturated fatty acids in the goldfish testis. Biol. Reprod., 51: 131-139. 